\title{
TERCEIRIZAÇÃO DO TRABALHO E OS SINDICATOS: TENDÊNCIAS E DESAFIOS NO SETOR DE TELECOMUNICAÇÕES
}

\section{Savio Machado Cavalcante ${ }^{1}$}

\begin{abstract}
RESUMO
Este artigo objetiva traçar um panorama das principais configurações do trabalho presentes no setor de telecomunicações brasileiro na atualidade, em especial o aumento das terceirizações, bem como indicar alguns dos desafios impostos aos sindicatos nesse contexto inaugurado, sobretudo, com a privatização das companhias estatais. Para tanto, utilizam-se pesquisa própria e outros trabalhos referentes a estudos de caso em São Paulo, Minas Gerais e Paraná, os quais apontam, em comum, tendências à precarização das formas de trabalho e diminuição do poder da ação sindical.

Palavras-chaves: terceirização, sindicalismo, telecomunicações, privatização
\end{abstract}

\section{ABstract}

This article intends to show the main configuration of the labor in brazilian telecommunication sector nowadays, in special the increase of the outsourcing, as well as indicate some of the challenges taxes to the unions in this context inaugurated, over all, with the privatization of the state companies. For in such a way, one uses proper research and other referring works the studies of case in São Paulo, Minas Gerais and Paraná, which in common show trends to precarious work forms and reduction of the power of the action filed by labor union.

Key-words: outsourcing, unionism, telecommunication, privatization

\section{Introdução}

A preparação feita pelo governo de Fernando Henrique Cardoso para a privatização das companhias de telecomunicações estatais, processo findo em 1998, incluiu a tentativa de se conformar um clima favorável ou, ao menos, de passividade entre os trabalhadores. As promessas eram variadas e tinham como respaldo a expectativa quase certa de que a expansão dos serviços aumentaria o mercado do setor, de forma que o futuro que se aproximava só traria melhorias e boas oportunidades para os trabalhadores. Para Fernando Xavier Ferreira, então presidente da Telebrás (e, bom lembrar, atual presidente da Telefônica no Brasil), qualquer que fosse o destino da holding

'Sociólogo, professor do Departamento de Ciências Sociais da Universidade Estadual de Londrina 
e de suas subsidiárias estaduais, nada "afetaria a rotina das pessoas" ${ }^{2}$. Em outra ocasião, na revista Teleconexão, feita especialmente para divulgar entre os trabalhadores as teses governistas, Ferreira afirmava que, devido aos grandes investimentos esperados, novas oportunidades de emprego seriam criadas em empresas que "nascerão mais fortes, com mais recursos e com maior capacidade de prestação de serviços à população". Para dourar um pouco mais o panorama traçado, dizia que "tudo isso [ocorrerá] em um cenário de competição e de busca de excelência" ${ }^{3}$. Uma matéria na mesma revista, com o sugestivo título de "Atenção especial aos empregados" fornece, de forma clara, o tom da idéia a ser passada:

Mudanças profundas, como as que estão sendo introduzidas no setor de telecomunicações do Brasil, costumam deixar apreensivos os funcionários das empresas envolvidas. A principal preocupação é, em geral, com a possibilidade de haver demissões. A preparação da privatização do Sistema Telebrás, porém, não envolverá mudança na politica de pessoal quanto à dispensa de empregados. A expectativa é de que, passado ao controle privado, o setor faça grandes investimentos, podendo gerar novos postos de trabalho. ${ }^{4}$

discurso oficial, tão bem fundamentado nos termos que dão legitimidade à "moderna" administração de recursos humanos, exibe, na verdade, duas faces. A primeira, coerente com a realidade e verificada com o passar do tempo, é a elevação de postos de trabalho nos diversos segmentos do setor, conseqüência lógica da entrada de novas companhias e da criação de novos serviços. A segunda face, referente à qualidade do trabalho e à forma pela qual as mudanças iriam ocorrer, foi decididamente falaciosa e buscava escamotear um cenário que vinha se desenhando desde os anos de 1990, qual seja, de reestruturação produtiva, gerencial e organizativa que, por sua vez, gerava uma tendência à precarização da mão-de-obra, achatamento de salários e ataque às organizações sindicais, entre outros elementos. Tanto o é que, para J. Bernardo 5 , o fato de muitas empresas já estarem sendo geridas enquanto companhias privadas, mesmo que ainda sob a posse estatal, ajuda a entender o porquê da relativa passividade e dificuldades de mobilização dos trabalha-

\footnotetext{
${ }^{2}$ FERREIRA, Fernando X. apud PRATA, José et al., Sérgio Motta - o trator em ação. São Paulo: Geração Editorial. 1999, p. 131.

3 Idem, "Privatização criará novas oportunidades de emprego", revista Teleconexão, n 1, março de 1998 , p. 2.

4 "Atenção especial aos empregados", revista Teleconexão, op. cit., p. 3

${ }^{5}$ BERNARDO, J. Transnacionalização do Capital e fragmentação dos trabalhadores - Ainda há lugar para os sindicatos?, São Paulo: Boitempo, 2000, p. 20.
} 
dores, os quais já sofriam as conseqüencias da flexibilidade e da perda de estabilidade no trabalho ${ }^{6}$.

Vários elementos caracterizam, atualmente, os tipos e a forma de trabalho no setor de telecomunicações, muitos deles surgidos a partir da década de 1970 com o advento de novas tecnologias responsáveis pela digitalização dos processos e das estruturas das empresas, as quais, em muitos casos, resultam em redução da força de trabalho. Mas aí reside somente uma parte da reestruturação. A outra se vincula intimamente às alterações na maneira de se contratar e organizar a força de trabalho, propiciadas pelo ambiente favorável à expansão das políticas neoliberais.

Assim, ao contrário da propaganda governista que negava mudanças "na política de pessoal quanto à dispensa de empregado", tão logo assumiram as estatais os novos proprietários implantaram uma vigorosa onda de demissões, voluntárias ou não, aposentadorias forçadas, contratos mais flexíveis e relacionamento individualizado com os trabalhadores com o intuito de tornar o sindicato um ente supérfluo.

As reestruturações já vinham ocorrendo nas empresas de telecomunicações no Brasil desde o início da década de 1990, mas a privatização representou o início das transformaçōes mais profundas e abrangentes, que levaram ao limite as formas de terceirização do trabalho, por exemplo. É certo que a homogeneidade nunca foi um traço definidor da classe trabalhadora, mesmo dentro de setores específicos. Todavia, não há como desconsiderar o intenso processo de diversificação que vem ocorrendo nas últimas décadas. Nas telecomunicações, em particular, soma-se a esse quadro a convergência tecnológica, que extinguiu profissões e criou serviços e produtos que demandam novas e diversas formas de trabalho. À figura tradicional do "telefônico" foram agregados, por exemplo, os milhares de operadores de call centers, prestadores de serviços variados, técnicos em informática, entre outros.

Todos esses elementos impuseram desafios muito grandes à ação sindical. A princípio, a causa mais evidente era a mudança do interlocutor principal, ou seja, o Estado dava lugar a proprietários privados que impunham formas notadamente diferenciadas de negociação, abertamente ofensivas e interessadas muito mais na relação individual com cada trabalhador. Em segundo lugar, os sindicatos precisaram se acostumar à falta de poder de mobilização e de barganha. Se nas décadas anteriores a força de trabalho

\footnotetext{
' A análise da trajetória do processo de privatização, os grupos envolvidos e a oposição realizada por entidades sindicais no pais são temas tratados em: CAVALCANTE, Sávio. Sindicalismo e privatização das telecomunicaçōes no Brasil: a busca (fracassada) à social-democracia. Dissertação de Mestrado, Campinas, IFCH, UNICAMP, 2006.
} 
caracterizava-se pelos altos indices de sindicalização e por garantias e benefícios estipulados em lei, a situação atual inverteu essa condição através das demissões que dizimaram os empregos formais - criando um sentimento de insegurança e instabilidade que se transforma em obstáculo à ação sindical e por meio das diversas formas de flexibilização da jornada e da remuneração do trabalho. Por fim, a diversificação trazida por novos serviços dentro do setor, aliada ao uso intenso das terceirizações, provocou uma baixa considerável na base de sustentação dos sindicatos tradicionais, que se viram em competição com uma gama de novas e antigas organizações, como as relativas à construção civil, aos prestadores de serviço, ao comércio, etc., as quais passam a disputar a representatividade legal dos trabalhadores. Esse elemento também indica que a unicidade sindical, característica ainda presente da estrutura corporativista atrelada ao Estado, tem perdido seu significado e valor real à medida que não impede a criação de milhares de entidades sindicais que, não dificilmente, disputam as mesmas bases de representação.

Indicaremos, a seguir, aspectos relativos a uma das práticas mais utilizadas no setor - a terceirização - para, em seguida, acompanhar alguns estudos que ilustram esse cenário.

As 'afinidades eletivas' entre as telecomunicações e a terceirização

A terceirização (ou subcontratação) ${ }^{7}$ existe desde os primórdios do capitalismo, de início, sob as vestes do "trabalho domiciliar" e, posteriormente, foi importante na estruturação de setores, como o automobilístico, ao construir redes de subcontratação em torno de grandes corporações. ${ }^{8} \mathrm{O}$ movimento básico que a define é a transferência, por uma empresa, de partes do processo de produção, ou de serviços vinculados a esse processo, para uma outra empresa ou para um trabalhador "autônomo", criando uma relação de subcontratação e diferenciação de coletivos de trabalho. Esse formato pode adquirir as mais variadas formas, de acordo com o contexto histórico, com as atividades em questão e com as empresas envolvidas. $O$ mais comum, na atualidade, é a relação de subcontratação entre uma grande empresa,

\footnotetext{
7 Para expressar essa tendência, usamos como sinônimos os termos terceirização e subcontratação, embora em alguns casos, ou na leitura de alguns autores, possam haver algumas distinções. Uma outra observação importante, como lembra Paula Marcelino (A logistica da precarização. São Paulo: Expressão Popular, 2004, p. 10), é que, na linguagem cotidiana, os trabalhadores nessas condições são chamados de "terceirizados", quando na verdade são "subcontratados", pois as atividades em si que são terceirizadas e não o trabalhador .

${ }^{8}$ Cf. DRUCK, M.G. Terceirização: (des)fordizando a fábrica. Salvador: ed. da Universidade Federal da Bahia; São Paulo: Boitempo Editorial, 1999, p. 153-157.
} 
"tomadora de serviços", e médias ou pequenas empresas, "prestadoras de serviço", embora exista também o movimento inverso ou mesmo relações de subcontratação entre pequenas empresas. Essa prática muitas vezes também é designada como externalização de atividades, mas se deve lembrar que, em vários casos, o trabalho em si continua a ser feito no interior da empresa que terceiriza, ocorrendo somente a diferenciação (interna) do estatuto de emprego dos trabalhadores. Há, de fato, uma miríade de configurações, de difícil classificação, mas vejamos mais de perto os pontos básicos que envolvem essa questão.

A forma atual, que originou mais propriamente o termo terceirização, é a subcontratação que tem como objetivo o provimento de serviços considerados de apoio, como vigilância, limpeza, alimentação, jardinagem, transporte, etc. Essa tendência era fruto, na visão de uma gama de autores e empresários que discutiam os rumos da "moderna" administração de recursos humanos ${ }^{9}$, da "globalização" da economia e da necessidade de aumento de produtividade e competitividade tendo em vista o mercado internacional. Nessa visão, a questão pode ser resumida em um princípio geral, a saber, "tudo o que não consiste em atividade essencial de um negócio pode ser confiado a terceiros"10. O resultado seria um aumento na agilidade das empresas, da produtividade dos trabalhadores e da qualidade dos produtos. ${ }^{11}$ No entanto, condenam uma "má terceirização" que existiria, sobretudo no Brasil, para a simples redução de custos, mascarando relações de emprego com vistas a burlar direitos constitucionais. Este tipo, caracterizado pela subordinação diretà da empresa prestadora à tomadora de serviço, traria desemprego e não teria nada em comum com a terceirização sobre a qual versam: a terceirização, para esses, é aquele "termo filosófico moderno positivo", que não causa desemprego e diminuição da contribuição sindical ${ }^{12}$.

O crescimento das práticas de terceirização por várias empresas no país demandou mudanças profundas na legislação trabalhista. A mudança mais importante ocorreu em 1996 com o Enunciado (Súmula) 331 do TST (Tribunal Superior do Trabalho), que admite várias exceções ao Enunciado 256, que até então regulamentava o assunto. Em síntese, o TST mantinha a ilega-

\footnotetext{
9 Trabalhos como: QUEIROZ, Carlos A. S. Manual de terceirização. São Paulo: STS, 1995; LEIRIA, Jerônimo S. Terceirização. Porto Alegre: Sagra-DC Luzatto, 1992; LEIRIA, J. S. et al. Terceirização passo a passo - O caminho para a administração pública e privada. Porto Alegre: Sagra-DC Luzatto, 1992; CAVALCANTE JR., Ophir A terceirização das relações laborais. São Paulo: LTr, 1996.

${ }^{10}$ LEIRIA, J. op. cit., p. 22.

$"$ Cf. LEIRIA, op. cit.; LEIRIA et al., op. cit.

${ }^{12}$ Cf. LEIRIA et al., op. cit.
} 
lidade da terceirização, pois induzia vínculo empregatício do trabalhador com o tomador de serviço, contudo, abria um vasto leque de ressalvas: além do trabalho temporário, de serviços de vigilância, conservação e limpeza - já liberados -, a contratação por empresa interposta era permita desde que os serviços fossem ligados à "atividade meio" do tomador e inexistindo a pessoalidade e subordinação direta a essa empresa contratante. A Súmula também abria exceção para a terceirização quando se tratasse da Administração Pública, o que possibilitou, em diversas áreas, a privatização periférica e indireta dos serviços públicos.

Ocorre que devido a essa abertura, de amplitude tão elevada, pouco, ou quase nada, ainda é considerado ilegal quando empresas se dispõem a terceirizar. A razão das facilidades propiciadas por essas exceções é que as definições de "atividades-meio" e "atividades-fim" são muito pouco objetivas e permitem grande espaço para interpretações variadas.

Quando se pensa essas possibilidades vindas com a terceirização se entende porque tão fortemente esta prática tem sido aplicada nas telecomunicações. Afinal, como definir quem exerce ou não as atividades-fim de uma operadora de telefonia, ou mesmo quais são exatamente essas atividades? Se "prestar serviços de telecomunicações à população" é a finalidade básica dessas empresas, quem define que um instalador de rede telefônica não integra o núcleo da empresa? O setor desenvolve produtos imateriais, como é a comunicação entre pessoas, mas necessita desenvolver e manter enormes estruturas físicas para tal empreendimento. A verdade é que, mesmo por "critérios técnicos", torna-se muito dificil estipular a importância das atividades, pois, de fato, somente uma enormidade de trabalhadores, em funções e cargos distintos, pode propiciar, efetivamente, a finalidade proposta. Para o usuário, o resultado final é inusitado: do pedido de uma linha telefônica, à instalação, reparos, e reclamações em call centers, em suma, em todo seu processo de relação com uma companhia de telecomunicações, ele pode, em momento algum, entrar em contato direto com trabalhadores da empresa central.

Mesmo que as formas de terceirização não sejam homogêneas, isto é, não possam ser todas definidas enquanto precárias e voltadas unicamente à redução de custos, todas as operadoras que atuam no território nacional fazem uso desse expediente, majoritariamente de forma negativa para o trabalhador. O que nos leva a uma importante indagação: como pode um setor tão marcado pelas rápidas e profundas transformações tecnológicas necessitar desse tipo de artifício? Parece-nos correto que, como vários autores já apontaram, a incorporação isolada de tecnologias ao processo de produção, tendo em vista principalmente a base microeletrônica, não gera isoladamente grandes ganhos, os quais somente são auferidos com reestruturações 
organizacionais e "reengenharias"13. Outro movimento que corrobora essa tendência é a formação de empresas prestadoras de serviço que pertencem aos mesmos grupos das grandes operadoras, recurso que possibilita um readequamento da força de trabalho em novas empresas "especializadas" em manutenção de redes, call centers, entre outras áreas das telecomunicações.

Um exemplo dessa tendência é dado por $\mathrm{M}$. Borges em sua análise sobre os impactos da reestruturação produtiva na operadora de telefonia CTBC (Companhia Telefônica do Brasil Central), atuante na região do triângulo mineiro, que, particularmente, foi a única empresa privada a coexistir com o Sistema Telebrás estatal. Preparando-se para as mudanças que ocorreriam no mercado com a privatização, a CTBC engendrou um grande processo de reestruturação organizacional, tendo como marcas características a implementação de programas de Qualidade Total, intenso uso de terceirizações (em qualquer tipo de atividade) e incremento das tecnologias digitais. A CTBC, nesse sentido, criou suas próprias terceirizadas, como a Engeset, responsável pela vigilância, manutenção e instalação de redes, e a ACS, empresa de call center. Os trabalhadores da empresa foram então deslocados a essas terceirizadas, sendo que em ambas os salários e benefícios foram drasticamente reduzidos. Essas transformações resultaram em intensificação do processo de trabalho, aumento da jornada e da "polivalência", ou seja, a necessidade de desempenhar múltiplas funções. A autora indica que tão ou mais importante que as novas tecnologias utilizadas foi a construção de uma estrutura que tentou criar uma "cultura de comprometimento" entre os trabalhadores, a partir do que seria uma "administração participativa". Esse fato foi até mesmo confirmado pelo diretor de $\mathrm{RH}$ da operadora (área designada por "talentos humanos" pela empresa), que estabelece como causa principal do enxugamento da empresa a "mudança de cultura" do grupo que se efetivou com o aumento das terceirizações. A autora afirma, ainda, que a adesão dos trabalhadores a esse projeto empresarial tem como motivação fundamental a ameaça do desemprego e o contexto negativo do mercado de trabalho. ${ }^{14}$

Em outro detalhado estudo sobre reestruturaçōes em operadoras de telefonia, S. Wolff pesquisou a trajetória de desenvolvimento da Sercomtel, de Londrina, uma das poucas empresas municipais de telecomunicações que,

${ }^{13}$ T. GOUNET (Fordismo e toyotismo na civilização do automóvel. São Paulo: Boitempo, 1999, p. 33) já advertia que, quando se pensa o conjunto de transformações advindas principalmente com o ideário japonês do toyotismo e da "flexibilidade", as inovações tecnológicas, mesmo sendo importantes, só ganham sentido na prática a partir dos projetos de reestruturação organizacional que buscam o envolvimento integral do trabalhador com a empresa.

${ }^{14}$ Cf. BORGES, Marlene. Os impactos da reestruturação produtiva sobre o mercado de trabalho no setor de telecomunicações: o caso da empresa CTBC, Dissertação de Mestrado, UFU, Uberlândia, 2000, p. 87.89 e 106. 
ainda hoje, mesmo após uma privatização parcial, continua tendo como acionistas majoritários empresas estatais. Contudo, sua gestão é acentuadamente privatizada, obedecendo aos ditames mercadológicos existentes. A Sercomtel também é prova de que as transformações tecnológicas, que alteram padrões e comportamentos de trabalhadores, caminham junto com projetos de "reengenharia" da estrutura organizacional. Nesse sentido, verificouse na empresa, aliado à informatização dos mecanismos e digitalização do processo de comutação, a emergência de programas que objetivavam criar um processo de "aculturamento" dos trabalhadores aos novos valores da companhia. Foram exemplos o MPQ (Mudança, Participação e Qualidade) e PTE (Projeto de Transformação Empresarial), "programas de qualidade total" que geraram uma nova orientação mais voltada à área de marketing. Além de mudar substancialmente o trabalho no interior da empresa, os projetos ocasionaram um enxugamento do quadro de funcionários, resultado da utilização de terceirizações, planos de aposentadoria e demissão incentiva$\mathrm{da}$, que reduziram um conjunto de quase mil trabalhadores para, em pouco mais de um ano, 750. ${ }^{15}$

\section{Um breve olhar sobre o debate acadêmico}

Pode-se afirmar que há uma tendência comum em boa parte dos trabalhos acadêmicos que versam sobre terceirização que é descrever essa prática como se ela pudesse ser dividida em duas modalidades ${ }^{16}$, muitas vezes aceitando, acriticamente, o discurso empresarial que tenta separar "formas modernas" e "formas atrasadas". De um lado, vários trabalhos ressaltam que a terceirização pode se ajustar ao processo de busca de qualidade e competitividade pelas empresas, o que beneficiaria uma rede de subcontratadas ao dotá-la de tecnologias avançadas, empregos qualificados e não-precários. Por outro lado, existiria uma segunda modalidade de terceirização, sobretudo devido à cultura empresarial brasileira, que só se interessaria pela redução de custos a qualquer preço, diminuindo a qualidade dos produtos e precarizando as condições de trabalho. Muitas pesquisas centradas na realidade brasileira têm demonstrado profundas conseqüências negativas para os trabalhadores e para os sindicatos, mas, na maioria dos casos, quando se apontam críticas à

${ }^{15}$ Cf. WOLFF, Simone. O espectro da reificação em uma empresa de telecomunicações: o processo de trabalho sob novos parâmetros gerenciais e tecnológicos, Tese de Doutorado, IFCH, Unicamp, 2004. O número de trabalhadores da Sercomtel foi reduzido mais ainda, chegando a $545 \mathrm{em}$ 2002, segundo SILVA, Givaldo Alves. Reestruturação produtiva e sindicalismo em empresas de telecomuni. cações: o caso Sercomtel S/A. Dissertação de Mestrado, UNESP, Marilia, 2003, p.110.

${ }^{16}$ Como tambèm analisado por DRUCK, M. G., op. cit. 
terceirização, subentende-se que essas seriam apenas formas distorcidas, sobretudo devido a questões culturais do pais, de uma tendência mundial que acarretaria melhorias ao processo produtivo e às condições de trabalho. ${ }^{17}$ Algo semelhante, mutatis mutandis, à situação analisada por M. Piore e C. Sabel de "especialização flexível" na Itália.

Segundo A. Faria, para citarmos somente um exemplo, as "duas modalidades de terceirização" estariam presentes no Brasil. A primeira, que vem "dos países industrializados", designada como outsourcing total, gira em torno da busca do aumento de produtividade e qualidade a partir de um novo "posicionamento comportamental", o "ganha-ganha", baseado na parceria e satisfação das partes. Por outro lado, existiria um outsourcing tupiniquim, isto é, a terceirização predominante "ao gosto do atrasado empresarial brasileiro", na qual o objetivo é a obtenção de lucros em curto prazo, reduzindo-se custos de forma generalizada. Somente esta última forma levaria a uma situação de antagonismo com empregados e $\operatorname{sindicatos}^{18}$.

Existe uma preocupação - positiva, por sinal - em não absolutizar a precarização causada pela larga utilização dessas práticas, afinal, há uma diversidade de situações e casos específicos. Todavia, não parece razoável separar a terceirização entre um "tipo ideal" e práticas distorcidas, mas sim considerála uma estratégia inclusa num programa maior de reestruturação produtiva que busca alternativas à renovação da acumulação de capital e à quebra da resistência operária. De forma que, quando se define uma suposta "terceirização à brasileira", ignora-se um movimento muito mais complexo que atinge todos os paises do mundo. Principalmente quando se tem em vista a experiência japonesa, berço de várias técnicas consideradas "modernas". F. Chesnais lembra que o objetivo da transferência de atividades, para os grandes grupos japoneses, foi o de fazer "recair sobre firmas 'terceiras' os imprevistos conjunturais e para impor aos assalariados dessas firmas o peso

\footnotetext{
${ }^{17}$ Os estudos que apontam o que seriam benefícios da terceirização na economia do Brasil, como de ABREU et al., e de GITAHY, L. \& CUNHA, A. são ressaltados por RUDUIT, Sandro. "Relações interfirmas e emprego na rede de empresas: a experiência de externalização de uma empresa no setor de telecomunicações", Sociologias, Porto Alegre, ano 4, no 8, jul/dez 2002, p. 400-431. Segundo Ruduit, essas pesquisas relativizaram as caracteristicas negativas da terceirização no pais, pois identificaram empresas subcontratadas nas quais existiam ativa participação sindical, baixa rotatividade, utilização de mão-de-obra qualificada, manutenção dos principais direitos trabalhistas, "sustentando que o caráter assumido pelo trabalho nas empresas terceiras é variável, em face das diferentes circunstâncias que envolvem as empresas" (p. 421). Problematizaremos a seguir algumas dessas afirmações.

${ }_{18}$ Cf. FARIA, Aparecido. "Terceirização - Um desafio para o movimento sindical", in RAMALHO \& MARTINS (Orgs.), Terceirização: diversidade e negociação no mundo do trabalho, São Paulo: Hucitec, 1994, p. 43.
} 
da precariedade contratual, combinado com níveis de salariais bem inferiores" ${ }^{\prime 19}$. Como argumenta Druck:

Não há como contrapor 'redução de custos' versus 'qualidade, produtividade, competitividade', pois, para se atingir os novos padrões de competitividade, exigidos pela reordenação do mercado internacional, o 'tripé' custos, qualidade e produtividade é o principal sustentáculo não somente da terceirização, mas do modelo japonês no seu conjunto; até porque o processo de melhoria de qualidade significa, geralmente, redução de custos. ${ }^{20}$

E, no tocante ao quadro verificado no Brasil, não obstante situações isoladas, a regra, de fato, tem sido a tendência de precarização crescente do trabalho, do emprego e das condições de saúde do trabalhador ${ }^{21}$, tornando aquilo que se chama de "distorção", algo essencial às reestruturações produtivas.

Os sindicatos na defensiva: terceirizações e mudanças do trabalho no período pósprivatização

A vinda de novas empresas para o país e as obrigações das novas operadoras de telefonia em cumprir as metas estabelecidas pelo governo fizeram com que o número de empregos originados pelo setor de telecomunicações crescesse muito intensamente nos primeiros anos, mas já sofrendo um declínio a partir de 2001, com o esgotamento do periodo inicial de grandes investimentos. Mas esse crescimento efetivou-se, sobretudo, através de empregos indiretos, conseqüência do amplo uso das terceirizações como forma de suprir as atividades necessárias nesse momento de desenvolvimento rápido. Segundo estudo realizado para o $\mathrm{BNDES}^{22}$, a expansão dos empregos no setor pode ser considerada extremamente desbalanceada, já que a elevada ampliação do emprego indireto ocorre em paralelo ao decréscimo do empre-

\footnotetext{
19 CHESNAIS, F. A mundialização do capital. São Paulo: Xamã, 1996, p. 35. Caso exemplar é o estudo de MARCELINO, P. , op. cit., que aponta as formas de terceirização utilizadas pela Honda no Brasil, causadoras de rebaixamento de salários, perda de direitos e de divisão política entre os trabalhadores. A estratégia da montadora japonesa foi criar, sob outro nome, uma empresa "especializada em logística", inserindo diferentes "tipos de trabalhadores" no mesmo processo de produção.

${ }^{20}$ DRUCK, M. G. op. cit., p. 149.

21 Cf. Ibid., p. 153.

${ }^{22}$ Cf. "Evolução do nivel e perfil do emprego direto e indireto no setor de telecomunicações no Brasil”, UNIEMP, CELAET, São Paulo, 2002.
} 
go direto a níveis muito abaixo do contexto anterior à privatização. ${ }^{23} \mathrm{O}$ crescimento de empregos indiretos foi de $332 \%$ e a diminuição de diretos em torno de $20 \%$. Assim, em 2001, 67,7\% do total dos empregos no setor eram indiretos, contrastando com os $27,7 \%$ de 1998 , o que demonstra aos pesquisadores um processo irreversivel no que se refere à forma de contratação, ou seja, novos trabalhadores somente são contratados por meio de terceirizadas.

A intensa utilização de contratações por via indireta é explicada, em parte, pela necessidade de serviços especializados e o período particular de crescimento acelerado. Contudo, outras razões mostraram-se de suma importância, principalmente quando se observam os pressupostos gerais que norteiam as reestruturações das empresas. Assim, ao mesmo tempo em que esse movimento pode ser entendido como uma arma econômica para redução de custos e, em alguns casos, até mesmo ganhos de qualidade (bom frisar, para a produção e não para o trabalhador em geral), um fator comum a todas essas experiências é a dissolução de coletivos de trabalho, ou seja, a desintegração de grupos e diferenciação em estratos de emprego, o que tem afetado a organização política dos trabalhadores.

O estudo de $\mathrm{M}$. Borges sobre a CTBC revela que para Luiz A. Garcia, presidente do grupo ALGAR, controlador da operadora, diminuir o poder do sindicato foi o motivo principal do uso das terceirizações:

(...) o sindicato que vinha fazer pressão, fazer greve na porta da empresa. Qual era o público-alvo dele dentro da empresa? Era o pessoal mais humilde, o pessoal de serviços gerais, de um e dois salários mínimos (...) este pessoal é necessário e nós então terceirizamos todos esses serviços gerais e com isso a força do sindicato na porta da empresa diminui consideravelmente (...) A pressão do sindicato em cima da empresa que nos forçou a fazer essa terceirização mais rápido ainda (...) Dentro desse setor sindical, hoje nós fortalecemos bastante todos os nossos colaboradores, os nossos funcionários, de modo que eles negociam com a empresa todos os reajustes, depois nós vamos até o sindicato só para homologar. Não com a presença de pessoas estranhas dentro da empresa, negociando para o funcionário. ${ }^{24}$

\footnotetext{
${ }^{23} \mathrm{Na}$ verdade, se consideradas somente as empresas diretamente ligadas a companhias de telecomunicações, como é a abordagem dos dados da RAIS do Ministério do Trabalho, o número de empregos chegou a cair de 1997 a 2000. E o emprego indireto no setor, segundo um dos critérios utilizados pelo estudo baseado em dados da ANATEL, envolve vários segmentos como: assistência técnica a clientes; instalação e manutenção de cabos e linhas de assinantes; instalação e manutenção de equipamentos de telecomunicaçōes; pesquisa e desenvolvimento; serviços de atendimento ao consumidor; projetos de engenharia; processamento de dados e digitação; limpeza, segurança e portaria; restaurante e cantina; conservação, manutenção e reparo de instalaçōes fisicas e transporte.

${ }^{24}$ GARCIA, L. A. apud BORGES, M., op. cit., p. 71, itálicos nossos.
} 
A fala do presidente da operadora é extremamente emblemática em vários sentidos. Em primeiro lugar por assumir, não obstante os discursos sobre "finalidades" básicas da empresa, que todos trabalhadores são necessários para a realização dos serviços em telecomunicações. Em segundo lugar, essa postura mostra que o ataque à ação sindical foi prioritário quando se modelam formas diversificadas de contratação de empregados. Assim, buscase uma relação mais individualizada com os trabalhadores, oposta a organizações coletivas que seriam "estranhas dentro da empresa". O intuito é tornar o sindicato apenas um ente legitimador, cabendo apenas a função de homologar acordos já realizados no âmbito individual.

Os números da CTBC mostram que o aumento de produtividade e ganhos com novos serviços são inversamente proporcionais à criação de empregos diretos na operadora. Entre 1988 e 1998, a capacidade de instalação de telefonia fixa aumento em $89,9 \%$ e, na telefonia móvel, de 1993 a 1998 , em $4.639,9 \%$, repercutindo em crescentes lucros líquidos e operacionais. Por outro lado, nesse mesmo período, a força de trabalho na companhia foi reduzida em torno de $75 \%$, de 2.509 trabalhadores, em 1989 , para 1.336 em 1998. ${ }^{25}$ O Grupo ALGAR em conjunto, no qual também estão presentes empresas diversas do ramo das telecomunicações, possuía, em 1988, mais de 13 mil funcionários, número que foi reduzido para menos de 6 mil em 1999. Para A. Garcia, isso mostra o sucesso da reestruturação, já que, nas suas palavras, "é a mesma empresa, com o mesmo faturamento, funcionando, talvez melhor. Com menos gente, você tem um pessoal de nivel maior" ${ }^{26}$.

$\mathrm{O}$ ataque às organizações sindicais também foi realizado, na CTBC, através da criação de um "Comitê de Associados" pela empresa, segundo explica S. Cunha, em outro estudo sobre a operadora. Advindo de "Programas de Qualidade Total" (PQT's), o objetivo do Comitê era servir de alternativa, para o trabalhador, ao sindicato, fazendo com que seus integrantes se envolvessem cada vez mais com os interesses da empresa. S. Cunha indica que esse espaço servia de correia de transmissão do núcleo dirigente da CTBC e incidiu negativamente na organização política dos trabalhadores realizada pelo SINTTEL-MG (Sindicato dos Trabalhadores em Telecomunicações). ${ }^{27}$

A competitividade da CTBC e a manutenção de sua alta lucratividade - que, por sinal, a possibilitou participar com sucesso do leilão da Telebrás - se efetivaram através desse processo de enxugamento da empresa via

\footnotetext{
${ }^{25}$ BORGES, M., op. cit., p. 86

${ }^{26}$ Garcia, A. apud BORGES, M. , op. cit., p. 86.

${ }^{27}$ Cf. CUNHA, Sebastião F. A reestruturaçâo produtiva na CTBC Telecom e os impactos para a organização de trabalhadores - o caso SINTTEL-MG, Dissertação de Mestrado, UFU, Uberlândia, 2002.
} 
terceirizações. Para os que permaneceram na empresa principal, a intensificação do trabalho foi acentuada com a adoção dos PQT's. Segundo pesquisa de Cunha, 93\% dos trabalhadores entrevistados disseram que a quantidade de trabalho havia sido aumentada, $87 \%$ afirmaram que o ritmo de trabalho ficou mais intenso e $57 \%$ admitiram levar, constantemente, trabalho para se fazer em casa. ${ }^{28}$

Os ganhos econômicos da operadora com as terceirizações, para não falar dos políticos, são facilmente visiveis. Quando se terceirizou o setor de rede para a Engeset, empresa do mesmo grupo ALGAR, os trabalhadores executaram, no dia seguinte, as mesmas atividades, mas recebendo $16 \%$ a menos de salário e tendo a jornada semanal aumentada em 4 horas, ou seja, as 40 horas, uma conquista que levou anos para ser obtida, se transformaram em 44 horas semanais. Com relação à outra empresa criada pelo grupo ALGAR, a ACS Call Center, a ela foram direcionados todos os serviços de atendimento da CTBC. Os resultados são expressivos: as remunerações decaíram, em média, em $48 \%$, e não havia a garantia de nenhum dos benefícios trabalhistas conquistados na CTBC. ${ }^{29}$

Esses mecanismos afetaram o poder de base dos sindicatos. A parir da introdução dos PQT's, terceirizações e do Comitê de Associados, a empresa conseguiu desestimular a atividade sindical. Em julho de 1996, a taxa de sindicalização na CTBC, que era de $44,61 \%$, decaiu pela metade, girando em torno de $21 \%$ em fevereiro de 2002. O SINTTEL-MG, filiado à CUT, possuidor de um histórico de contestação e importantes greves, segundo aponta Cunha, não tem conseguido reverter as conquistas empresariais, debilitado pelo decréscimo de sua base e pela distância em relação aos trabalhadores. ${ }^{30}$ A luta atual é conseguir a representação do conjunto dos trabalhadores espalhados pelo setor, tentando conquistar melhores condições de trabalho para as terceirizadas, subcontratadas e empreiteiras.

De fato, esse parece ser o grande desafio do sindicalismo em telecomunicações da atualidade, ou seja, inverter o processo de fragmentação dos coletivos de trabalho e adquirir a representação de todos os trabalhadores que integram as centenas de grandes e pequenas empresas do setor.

Em São Paulo, tem sido essa a principal estratégia do SINTETEL , ligado à Força Sindical, após a privatização. Seus diretores defendem o que

\footnotetext{
${ }^{28}$ Cf. Ibid., p. 21.

${ }^{29}$ Cf. Ibid., p. 108-9.

${ }^{30} \mathrm{Em}$ outro estudo sobre esse sindicato, GRACIOLLI, E. \& SILVA, S. ("Os novos paradigmas do trabalho e a mutação do sindicalismo", paper em www.sep.org.br) afirmam que a diretoria atual tem se voltado para as temáticas sintonizadas com o discurso hegemônico na CUT, de sindicalismo cidadão e a ação sindical pautada no diálogo com governos e patronato.
} 
seria uma postura voltada à negociação "moderna e profissionalizada" que, ao contrário de muitos outros sindicatos, o permitiu abarcar um contingente maior de empresas no setor, tendo, assim, sua base ampliada. $O$ estudo de R. Uchima confirma esse movimento. A partir de dados do sindicato, o autor indica que a base representada se elevou de 30 mil, em 1980, para 40 mil, em 1995, e, após a privatização, atingiu 100 mil trabalhadores em 2003.

Contudo, o aumento da base representada e, consequentemente, a elevação das contribuições sindicais não resultaram em conquistas ou mesmo manutenção de direitos e benefícios adquiridos historicamente, como pode fazer parecer o discurso do sindicato. Segundo Uchima, após a privatização, o trabalhador da antiga Telesp, agora Telefônica, só acumulou perdas, não somente quanto à queda das remunerações, mas também relativas à intensificação do trabalho, extensão de jornada, perda de benefícios e demissões em massa. ${ }^{31}$ Também o estudo de S. Oliveira, sobre a cadeia produtiva de telecomunicações em São Paulo, aponta que as alterações trazidas pela Telefônica no tocante à composição do perfil do trabalho e dos padrões de contratação apresentam como tendência básica a precarização das relações de trabalho. ${ }^{32}$

Tão logo assumiu o comando da maior operadora estadual de telecomunicações do Brasil, a Telefônica iniciou um grande projeto de reestruturação organizacional para, segundo a empresa, adequá-la ao ambiente competitivo que se instalava. Devido à sua estratégia de internacionalização, a companhia espanhola já possuía um forte histórico no tocante a planos de reestruturação e, na maioria dos casos, com pouca ou nenhuma abertura à participação efetiva de organizações sindicais. A única garantia conquistada pelo SINTETEL foi um prazo de 6 meses, após o leilão, no qual a empresa se comprometia a não promover demissões. Findo o prazo, uma das mais fortes reduções de contingentes de trabalhadores no setor foi executada, através de PDI (Programa de Desligamento Incentivado), terceirizações e demissões. O gráfico abaixo indica essa linha descendente.

\footnotetext{
${ }^{31}$ Cf. UCHIMA, Ricardo. O processo de flexibilização das relações de emprego no setor de telecomunicaçōes do estado de São Paulo: o caso da empresa Telefônica, CESIT/ DIEESE, 2005, p. 47.

${ }^{32}$ Cf. OLIVEIRA, Sirlei. Reestruturação das Telecomunicações no Brasil: uma (re)visão das estratégias de gestão da produção e das relações de trabalho na cadeia produtiva. Tese de Doutorado, FFLCH, USP, São Paulo, 2004.
} 


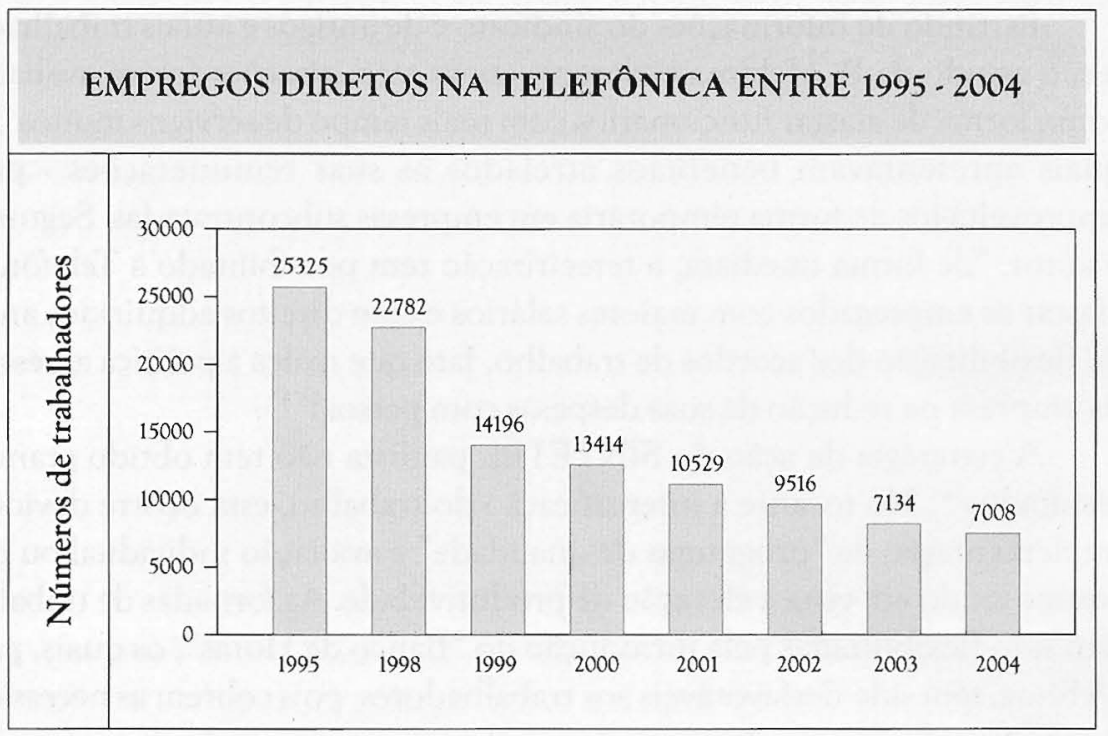

A produtividade da operadora, calculada pela quantidade de linhas para cada trabalhador, chegou a patamares superiores até mesmo aos encontrados em empresas mundiais que se reestruturam há muito mais tempo, evidenciando a força do "enxugamento" realizado. Abaixo seguem os índices aproximados até o ano de 2001.

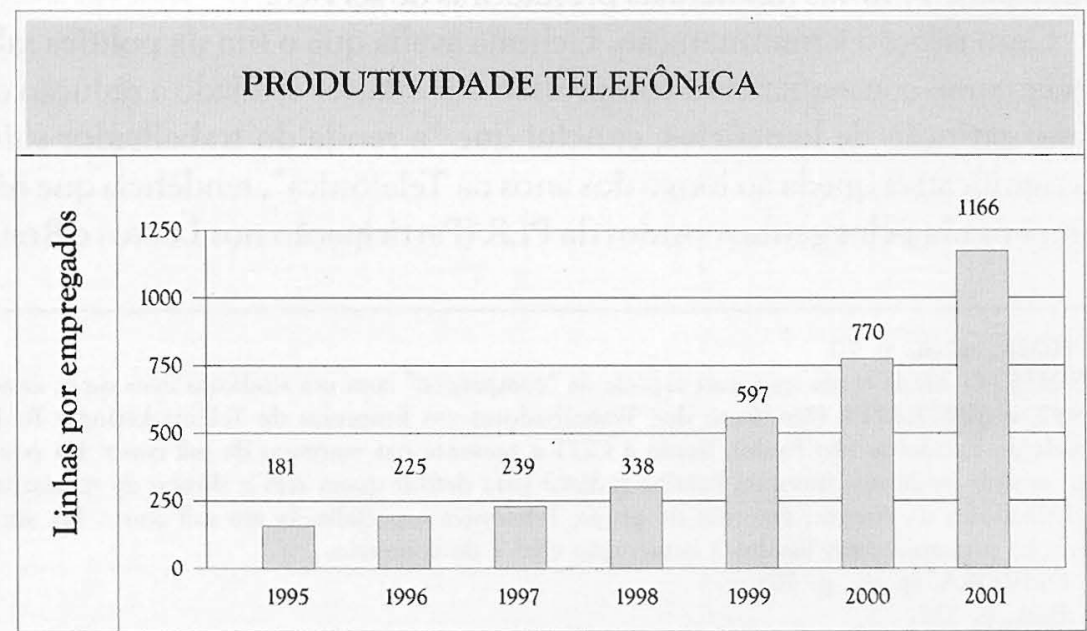


Partindo de informações do sindicato e de antigos e atuais trabalhadores, o estudo de R. Uchima esclarece que as terceirizações foram avaliadas como forma de afastar funcionários com mais tempo de serviço - muitos dos quais apresentavam benefícios atrelados às suas remunerações - para reaproveitá-los de forma temporária em empresas subcontratadas. Segundo o autor, "de forma imediata, a terceirização tem possibilitado à Telefônica afastar os empregados com maiores salários e com direitos adquiridos antes da flexibilização dos acordos de trabalho, fato que realça a politica agressiva da empresa na redução de suas despesas com pessoal" ${ }^{33}$.

A estratégia de ação do SINTETEL paulista não tem obtido grandes resultados ${ }^{34}$. No tocante à intensificação do trabalho, esta ocorre devido à implementação de "programas de qualidade" e avaliação individual ou por equipe tendo em vista a elevação de produtividade. As jornadas de trabalho têm sido flexibilizadas pela introdução do "Banco de Horas", os quais, para Uchima, têm sido desfavoráveis aos trabalhadores, pois cobrem as necessidades da empresa de acordo com a demanda sem a contratação de mais trabalhadores e impossibilitam a remuneração de horas-extras, por sinal, cada vez mais comuns. S. Oliveira ainda indica a existência de vários "Bancos de Hora paralelos que servem para burlar os que são contratados, indicando a pressão que as empresas realizam para ampliar a jornada, sem que haja remuneração". Segundo um entrevistado dessa pesquisa, os "bancos de horas clandestinos" são realizados para inviabilizar o controle das horas trabalhadas pelo sindicato, o que dificulta a cobrança e permite que horas-extras sem remuneração continuem sendo feitas ${ }^{35}$. Outro fator existente, quando se pensa o conjunto de empresas do setor, é que a jornada de trabalho de 40 horas semanais, conquistada na época da Telesp e mantida pela Telefônica, foi elevada para 44 horas nas demais prestadoras de serviço. ${ }^{36}$

Com relação à remuneração, Uchima avalia que o fim da política salarial teve como conseqüência a compressão dos salários e, aliado à redução ou mesmo extinção de benefícios, conclui que "a renda do trabalhador sofre uma significativa queda ao longo dos anos na Telefônica”, tendência que não é compensada pelos ganhos vindos da PLR (Participação nos Lucros e Resul-

\footnotetext{
${ }^{33}$ UCHIMA, op. cit., p. 70.

${ }^{34}$ O SINTETEL ainda conta com uma espécie de "competição" com um sindicato mais novo, criado em 1992, o SINTRATEL (Sindicato dos Trabalhadores em Empresas de Telemarketing e Rádio Chamada do Estado de São Paulo), ligado à CUT e presente nas empresas de call center. Há pouco tempo, os dois sindicatos travaram batalha judicial para definir quem tem o direito de representar os trabalhadores da Atento, empresa do grupo Telefónica especializada em call center. Há ainda competição com sindicatos ligados à construção civil e de comércio.

35 Cf. OLIVEIRA, op. cit., p. 368.

${ }^{36}$ Cf. Ibid., p. 335.
} 
tados) ${ }^{37}$. S. Oliveira ressalta, igualmente, a ampliação das "dificuldades para reposição de perdas salariais", com proposta de reajustes abaixo da inflação, além de formas variadas de diferenciação por faixas salariais. ${ }^{38}$

A detalhada pesquisa de S. Oliveira abarcou empresas representativas da rede de firmas que se encontram em volta da Telefônica e indicou que as diretrizes da empresa central são diferentes das praticadas nas prestadoras de serviço, o que gera a grande variação de condições de trabalho e formas de negociação coletiva.

Embora estejam todos com a mesma tarefa, que é garantir um serviço de qualidade com a grife Telefônica, o lugar ocupado por esses trabalhadores é muito diferenciado e o tratamento que eles recebem também. Há uma desigualdade muito grande entre os diferentes vínculos empregatícios. Uma coisa é "ser Telefônica" como os próprios trabalhadores dizem, outra coisa é "ser terceirizado". São mundos distintos, para os ocupantes dos diferentes níveis da cadeia produtiva. Os diferenciais salariais são grandes, seja na remuneração fixa ou variável. Há ainda grandes diferenças no pagamento dos benefícios que esses trabalhadores recebem dependendo da empresa que os emprega. ${ }^{39}$

O exemplo fornecido pela "Atento" é interessante para se pensar essas transformações. Essa empresa de call center foi especialmente criada pela Telefônica para suprir as necessidades da operadora no tocante ao tele-atendimento. As economias feitas começam pelo fato de que foi extremamente reduzido o número de estabelecimentos físicos que serviam de atendimento geral à população. Em segundo lugar, se os antigos tele-operadores da Telesp recebiam cerca de $\mathrm{R} \$ 1.000$ por essas funções, os empregados da Atento ganham, pelo mesma carga horária, valores abaixo de $\mathrm{R} \$ 400$. O sucesso desse empreendimento foi tanto que não só pela Telefônica a Atento é contratada, mas por empresas de vários segmentos, o que a fez se ampliar pelo território brasileiro e empregar atualmente cerca de 27 mil trabalhadores. As características maçantes do trabatho de tele-operador e o perfil médio dos trabalhadores - principalmente jovens - coadunam numa elevada taxa de rotatividade do trabalho: cerca de 200 pessoas são demitidas ou contratadas diariamente. ${ }^{40}$

Interessante, ainda, é notar que a Atento utiliza a seu proveito o fato de 'contribuir' na geração de postos de trabalho a categorias que expressam índices altos de desemprego - além dos jovens, mulheres acima de 40 anos. A empresa, então, busca justificar a flexibilização que demanda em acordos

${ }^{37}$ Cf. UCHIMA, op. cit, p. 50.

${ }^{38}$ Cf. OLIVEIRA, op. cit., p. 362.

39 Ibid., p. 329.

${ }^{40}$ Cf. Ibid., p. 348. 
- contratos temporários, jornada e remuneração reduzidas - por esses critérios, o que, acriticamente, têm sido defendidos pelo SINTETEL:

Os dirigentes sindicais (...) acreditam que a empresa age de boa fé e que realmente busca beneficiar jovens e mulheres acima de 40 anos. Esses dirigentes sindicais não questionam a qualidade dos empregos, a remuneração, as condições e ritmo de trabalho e, tão pouco, a fragilidade dos vínculos empregatícios oferecidos por esta empresa. Defendem que é melhor um emprego nessas condições do que nenhum emprego. ${ }^{41}$

E são esses mesmos sindicalistas, que acreditaram na gestão "profissionalizada", que têm sido banidos das já escassas formas de participação do controle das empresas. Baseada em análises dos acordos coletivos, S. Oliveira assinala que há forte tendência de restrição à ação sindical, pela eliminação de cláusulas que garantiam o acesso dos sindicatos às informações e dependências das empresas, assim como foram reduzidos os dirigentes liberados e a participação dos mesmos em fóruns de trabalhadores, como CIPA e comissão de PLR. ${ }^{42}$

A onda de terceirizações tem se alastrado até mesmo pelos centros de pesquisa, como na Fundação CPqD (o ex-Centro de Pesquisas e Desenvolvimento da Telebrás), o que se traduz em mais insegurança e precarização do trabalho nessas empresas, sem mencionar o sério obstáculo que se coloca à qualidade das atividades realizadas. O SinTPq (Sindicato dos Trabalhadores de Pesquisa, Ciência e Tecnologia de Campinas e região) sente o quadro adverso tendo em vista, por exemplo, a taxa de sindicalização. Com a privatização e a vinda de algumas empresas de equipamentos e tecnologias em telecomunicações, a base do sindicato tendeu a crescer, mas a taxa de sindicalização apresenta patamares bem menores do que meados da década passada. Segundo números retirados dos boletins do sindicato, os anos de 1995 e 1996 indicavam taxas de sindicalização, respectivamente, de 55 e $80 \%$, indice que em 2005 girava em torno de $23 \% .^{43}$

As tendências presentes nessas novas formas de contratação e manutenção da força de trabalho têm causado danos às atividades desses centros. Uma tendência que atesta os problemas enfrentados pelo $\mathrm{CPqD}$, por exemplo, é a alta rotatividade existente. Segundo dados do SinTPq, cerca de 700 empregados deixaram o Centro de 1998 a 2003, uma taxa altíssima tendo em vista que o número total de trabalhadores nessa época variou de 850 a

\footnotetext{
${ }^{41}$ Ibid., p. 348.

${ }^{42}$ Cf. Ibid., p. 363.

${ }^{43}$ Cf. CAVALCANTE, S., op. cit.
} 
pouco mais de 1000 . Uma rotatividade grande, especialmente de trabalhadores qualificados, é incompatível com qualquer centro de pesquisa digno de nome, haja vista que o sucesso da criação e desenvolvimento de produtos e projetos necessita de uma estratégia voltada ao longo prazo. $O$ aumento das terceirizações no Centro é parte explicativa dessa tendência. Em meados de 2003, o sindicato alertava que a abertura de licitação para contratação de empresas terceirizadas em softwares para telecomunicações acontecia após uma demissão em massa, na qual inúmeros analistas de sistema haviam sido dispensados $^{44}$. Em outra oportunidade, o SinTPq expôs os detalhes da prática:

Um ponto extremamente negativo da Fundação $\mathrm{CPqD}$ é o excesso de terceirizações. Elas atingem hoje até mesmo as atividades-fim e, pior, muitas vezes custeadas com recursos do FUNTTEL [Fundo para o Desenvolvimento Tecnológico das Telecomunicações]. A verba pública é repassada diretamente a outras instituições para realizar serviços que deveriam ser executados pelo Centro. Umas das formas mais comuns de terceirização encontradas no CPqD é a fabricação de autônomos, trabalhadores que são demitidos para serem contratados como consultores, o que deteriora as relações trabalhistas e tira o vínculo com a empresa, tanto do empregado como de seu conhecimento especializado. ${ }^{45}$

No Paraná, a situação não tem sido muito diferente. Desde a privatização da Telepar, operadora estadual do Sistema Telebrás e anexada à atual Brasil Telecom, o enxugamento organizativo via terceirizações fez com que o quadro de funcionários passasse, aproximadamente, de 5 mil para 2 mil trabalhadores $^{46}$, tendência semelhante à já citada Sercomtel de Londrina. $O$ SINTTEL paranaense tentou acompanhar as mudanças do setor através da mudança de seu estatuto, o qual passou a contemplar trabalhadores de empreiteiras, empresas de call center, provedores de internet, empresas de TV a cabo, entre outras. Dessa forma, a base representada cresceu significativamente, mais que dobrando o conjunto de 6 mil trabalhadores, antes da privatização, para 13 mil. Todavia, esse crescimento não redundou em aumento do poder sindical, já que a taxa de sindicalização, proporcionalmente, decresceu. Se antes existiam 5 mil sindicalizados, esse número só chega hoje à marca de 6 mil.47

\footnotetext{
${ }^{44}$ Cf. $\operatorname{SinTPq}$ Informa, $n^{\circ} 422,03 / 06 / 2003$.

${ }^{45}$ Cf. SinTPa Informa, n $428,29 / 08 / 2003$.

46 Cf. ARAÚJO, S. M. "A ação sindical no contexto politico da privatização das telecomunicações no Brasil", in Scripta Nova Revista Eletrónica de Geografia y Ciencias Sociales, vol. VI, n 119(100), agosto de 2002.

${ }^{47}$ Cf. ARAÚJO, S. M. et al., "O sindicalismo e o movimento do capital: bancários, metalúrgicos e telefonicos no Paraná/BR", paper do VIII Congresso Luso-Afro-Brasileiro de Ciências Sociais, Coimbra, Portugal, setembro de 2004.
} 
Assim, segundo Araújo et al., não foram supressões de benefícios e direitos em acordos que têm abalado as conquistas dos sindicatos, mas sim a cobertura cada vez mais reduzida que esses acordos refletem. A tendência, na verdade, é uma "pulverização" da ação coletiva, a qual precisa se integrar a um emaranhado de situações e particularidades encontradas em cada empresa. No diagnóstico realizado por M. Ferraz,

Não ocorreram grandes perdas no sistema de cobertura de benefícios quando se analisa, separadamente, as cláusulas do acordo coletivo firmado com a Brasil Telecom. No entanto, estas cláusulas não estão sendo generalizadas para outras empresas. A proteção social gerada pelo acordo firmado com a GVT - empresa de telefonia fixa, assim como a Brasil Telecom - está aquém desta. $\mathrm{O}$ mesmo ocorre nos acordos firmados com as empresas terceirizadas de instalação, as empresas de TV a cabo e os Call Centers. Na prática, enquanto havia cobertura para quase $100 \%$ da categoria através de um bom acordo coletivo antes da privatização, hoje esta cobertura não atinge mais que $25 \%$ da mesma. ${ }^{48}$

Com relação à orientação política do SINTTEL-PR, a postura explicitamente de confronto das décadas passadas deu lugar a formas, segundo Araújo et al., "pré-novo sindicalismo", calcadas na criação de sistemas de atendimento assistencial, que disponibiliza acessos a farmácias, colônias de férias e cursos variados. ${ }^{49}$ As antigas diretorias, alinhadas a tendências "de esquerda" da CUT foram se alterando num processo que deu espaço a correntes de visão participacionista da mesma central e, atualmente, é comandada por um grupo que a desfiliou da FITTEL (Federação Interestadual de Trabalhadores em Telecomunicações) e da CUT.

Analisando a postura do sindicato em relação à outra operadora paranaense, a Sercomtel, G. Silva aponta que a diretoria, mesmo quando ainda dirigida por lideranças cutistas, não levantou oposição às praticas empresariais, por defini-las enquanto "positivas e inexoráveis", incentivando a adesão dos trabalhadores aos programas relativos à reestruturação da operadora..$^{50}$

\footnotetext{
${ }^{48}$ FERRAZ, M. "Igualdade, desigualdade e diferença: desafios para o sindicalismo paranaense frente à pulverizaçāo dos acordos trabalhistas", paper do XII Congresso Brasileiro de Sociologia, Belo Horizonte, 2005.

${ }^{49}$ Cf. ARAÚjO et al., op. cit., 2004, p. 10.

${ }^{50}$ Cf. SILVA, G. A., op. cit. O autor cita uma passagem do jornal do sindicato de 1996: "Acreditamos que esses programas são de fundamental importância (...) isso será fundamental para tornar a Sercomtel competitiva internacionalmente e por conseqüencia melhorar as condições de vida de seus trabalhadores e da comunidade em que está inserida. Qualidade e eficiência é o que todos desejamos, direção da autarquia, funcionários e diretoria do SINTTEL. Não podemos ficar de fora" (p. 126.).
} 
Outro ponto muito interessante da situação atual do setor mostra-se a partir da análise das relações dos sindicatos com a Telemar, a operadora de telefonia que está presente nas regiões Norte, Nordeste e Sudeste. Interessante porque essa companhia é controlada exclusivamente por grupos nacionais, além do Estado via BNDES. Ou seja, seria algo muito próximo do modelo alternativo à privatização comandada por $\mathrm{FHC}$, o qual foi defendido pelo movimento sindical em torno da FITTEL, que tinha como uma de suas características a presença do capital nacional em oposição à entrega do patrimônio a grupos estrangeiros. A realidade mostra que a nacionalidade do capital tem sido um quesito muito pouco importante quando se toma a forma de relacionamento com os sindicatos e a desestruturação do trabalho no setor. Ao contrário, de acordo com o que tem sido verificado por dirigentes sindicais, a postura da Telemar é a mais ofensiva às organizações dos trabalhadores:

A Telemar foi a única empresa que não tem capital estrangeiro e que foi pior do que as outras no trato das relações sindicais e tratamento com os trabalhadores (...) [e comentando a relação com outras empresas, incluindo a Telemar diz que] as empresas já vão em frente, o que querem é negociar com os sindicatos redução de direitos. Então as empresas, diversas dessas empreiteiras, por exemplo, querem negociar e a pauta é a redução abaixo do que é previsto na lei. ${ }^{51}$

Comentando a prática intensiva de terceirizações pela Telemar, outro sindicalista menciona um elemento que, na visão dos apologistas da privatização, seria impensável no contexto do "mercado livre e aberto". O dirigente se refere à dificuldade de estabelecer negociações com empreiteiras de propriedade de senadores e deputados:

Na Telemar o estado de terceirização é extremamente precário, não linear, obedece características regionais e a interlocução do sindicato e essas empresas, em muitos casos, não acontece. Algumas empresas insistem que a representação se dará pela estrutura da empresa com o sindicato da construção civil. Nós temos buscado interlocução chamando a responsabilidade da empresa que contrata para esse debate, mas ainda é muito desigual, muito desnivelado. As características regionais e a interferếncia política ainda mandam muito. Muitas empresas pequenas como essas têm o mando do senador, do deputado ou coisa parecida. ${ }^{52}$

\footnotetext{
51 Dirigente sindical do SINTTEL-MG apud DIEESE, As negociaçôes coletivas e o emprego no setor de telecomunicações (1993-2001): um olhar sobre a privatização dos serviços, maio de 2002, p. 37.

52 Dirigente sindical da FITTEL apud DIEESE, op. cit., p.33.
} 
Ainda sobre o uso intensivo das terceirizações, cabe apontarmos o estudo de S. Ruduit sobre as relações construidas entre um conjunto de empresas do setor de telecomunicações no Rio Grande do Sul. Essa pesquisa teve como objeto a CRT e onze empresas subcontratadas, que em conjunto criam uma complexa rede de relação interfirmas, na qual foram verificadas diferentes condições de trabalho ao longo da rede de empresas. Segundo Ruduit, existiam tanto formas de emprego estável, com benefícios e direitos, quanto formas precárias, de baixa remuneração e com pouca atividade sindical. ${ }^{53}$

A análise do autor pode ser situada entre as pesquisas que abordam a terceirização como uma prática que pode ser separada em duas modalidades, como discutimos no item anterior. Assim, quando a empresa central estabelece vínculos baseados em "estratégias competitivas", de cooperação, sobre produtos técnicos mais complexos, haverá melhores condições para existência de formas estáveis e não-precárias de emprego. Por outro lado, se a relação é de subordinação e as intenções somente giram em torno da redução de custos, os contratos de trabalho geralmente têm sido precários. $O$ autor ainda afirma que "quanto mais próxima da empresa central estiver a empresa contratada, maiores seriam as chances de práticas não-precárias de emprego".

A ressalva apresentada pelo estudo é importante na medida em que as imposições do mercado são, realmente, absorvidas de forma diferenciada pelas empresas, provocando uma heterogeneidade de situações quando se pensam as formas de emprego. Contudo, o que nos parece essencial reter é que as "formas precárias" têm se mostrado fundamentais e funcionais à estruturação dos empreendimentos, os quais são cada vez mais calcados num conjunto de relações que não excluem a desqualificação da prática laboral e colocam como ponto primordial a desintegração de coletivos de trabalho. Como bem frisou um dirigente sindical, boas condições de emprego, ampliadas em toda a rede empresarial, são cada vez mais "desvantagens competitivas", as quais são evitadas na celebração de acordos gerais: "[as operadoras] tentam medir o que o outro está propondo para ver se eles não estão ficam em desvantagem competitiva. Desvantagem competitiva é pagar melhor, nesse caso" ${ }^{\prime 4}$.

O quadro pós-privatização é, nesse sentido, traçado da seguinte forma por um integrante do SINTTEL-RS:

As relações com as direções dessas grandes empresas terceirizadas são as piores possiveis, elas fogem do sindicato. Além dos terceirizados, temos outras realidades

${ }^{53}$ Cf. RUDUIT, op. cit

${ }^{54}$ Dirigente sindical da FITTEL e SINTTEL-MG apud DIEESE, op. cit., p. 38. 
que nos afligem e muito nos preocupam, são os trabalhadores autônomos quarteirizados que trabalham em pequenos grupos, todos irregulares. Outro grande problema é como o governo colabora com essa politica, as empresas estão abusando na contratação de estagiários para os trabalhos de rotinas de jornadas integrais, substituindo os trabalhadores efetivos e nas piores condições de trabalho. Faltam dirigentes para elaborar planos e estratégias de trabalho e para fiscalizar os A.C.T. e o cumprimento das leis. ${ }^{55}$

Assim, o desafio lançado aos sindicatos de telecomunicações atualmente corresponde à forma pela qual essas organizações darão respostas à complexificação e fragmentação das relações de trabalho. A mera "negociação" e "proposição" têm sido insuficientes num contexto em que as grandes empresas desfrutam do ambiente recessivo que provoca desmobilização frente à ameaça do desemprego.

Os desafios do sindicalismo em telecomunicações

As transformações pelas quais passou o capitalismo nas últimas décadas do século XX, e que se acentuam na atualidade, resultaram em novas problemáticas para a ação sindical, principalmente quando se tem em vista o trânsito exacerbado do ideário neoliberal em boa parte dos governos e, paradoxalmente, nas próprias organizações sindicais. Em muitos casos, o quadro político anterior a essas mudanças abria espaços para a celebração de pactos com a classe trabalhadora, possibilidades que têm se tornado cada vez mais raras.

Imersos numa conjuntura negativa, muitos se vêem obrigados a atuar "propositivamente" por condições "menos piores" de trabalho. As conquistas estabelecidas outrora são trocadas por garantias de permanência em zonas, cada vez mais restritas, de estabilidade.

A privatização das companhias estatais de telecomunicações inaugurou um periodo de grandes metamorfoses para os sindicatos no Brasil, principalmente pelo fato de essas entidades terem sido criadas e desenvolvidas tendo como interlocutor o Estado. $O$ forte poder de mobilização e barganha alterou-se por completo. As novas empresas, se valendo até mesmo de "negociadores profissionais" (por sinal, que também são subcontratados) buscam trazer para o seu lado - à sua maneira, logicamente - os dirigentes sindicais, ou seja, tentam transformá-los em gestores de empreendimentos que visam ao lucro e à competitividade.

${ }^{55}$ Dirigente sindical do SINTTEL-RS apud DIEESE, op. cit., p. 45. 
Pode-se dizer que a prática da terceirização, com a criação de redes complexas de subcontratação, tem se mostrado a principal arma empresarial para minar o poder sindical e dotar de "flexibilidade" as negociações, contratos, admissões, desligamentos, em suma, o manejo da força de trabalho. A heterogeneidade da classe trabalhadora, nesse novo contexto, é notadamente distinta das divisões anteriormente existentes e, abalados pelas conseqüências do neoliberalismo e acostumados à verticalidade da produção, os sindicatos têm encontrado muitas dificuldades para lidar com essa nova fragmentação.

A miríade de empresas que são criadas e colocadas na mesma cadeia produtiva das telecomunicações, através da terceirização de atividades e serviços, é marcada, na quase totalidade dos casos, pela preeminência de uma grande operadora que, vale ressaltar, age, principalmente no tocante à telefonia fixa, de maneira monopolista em seu mercado. Essa situação é emblemática para se entender os processos produtivos atuais, nos quais a descentralização ocorre tão somente na execução de tarefas e serviços, enquanto a gestão e o mando permanecem centralizados. As desigualdades também estão presentes na formas de emprego, já que núcleos de trabalhos altamente qualificados e estáveis convivem com a precariedade de contratos e condições de trabalho.

O futuro da ação sindical parece passar, cada dia mais, pela renovação de estratégias que fortaleçam o sentimento de coletividade e o enraizamento político no seio da classe trabalhadora, o que não exclui - ao contrário, pode mesmo exigir - a mobilização em torno de projetos de transformação social. 